Article

\title{
Senses of Echo Lake: Michael Palmer, Stanley Cavell, and the Moods of an American Philosophical Tradition
}

\section{Richard Deming}

Department of English, Yale University, New Haven, CT 06520, USA; richard.deming@yale.edu

Received: 11 April 2019; Accepted: 15 May 2019; Published: 19 May 2019

check for updates

\begin{abstract}
This essay explores a philosophical tradition that Stanley Cavell has traced out and which he emphasizes as being American inasmuch as it is arises out of the thinking of Ralph Waldo Emerson and Henry David Thoreau. It then investigates how the poems of the avant-garde poet Michael Palmer link with, overlap with, this strain of American philosophy in terms of how it enacts an understanding of what we might call "philosophical mood," on outlook based on the navigation of representation, generative self-consciousness, and doubt that amounts to a form of epistemology. The essay does not trace the influence-direct or otherwise of Cavell and his arguments for philosophy on the poems, despite a biographical connection between Cavell and Palmer, his former student. Instead it brings out the way that one might fruitfully locate Palmer's work within an American literary/philosophical continuum. The article shows how that context opens up the work to a range of important existential and ethical implications. I endeavor to show that Notes for Echo Lake, Palmer's most important collection, locates itself, its language, within such a frame so as to provide a place for readerly encounters with the limitations of language. These encounters then are presented as an opportunity for a deeper understanding of subjectivity and for attuning oneself to the role that active reading and interpretation might play in moral perfectionism.
\end{abstract}

Keywords: Ethics; Stanley Cavell; Michael Palmer; poetry; American philosophy; Ralph Waldo Emerson; poetics; language poetry; moral perfectionism

These days, we may be beyond a pro forma gesture justifying or rationalizing why it is that we might bring the weight of philosophy and its concerns to bear on the practice of reading poetry. In poetry, from the German, British, and American Romantics forward to the Modernists, and in philosophy, from Hegel to Heidegger to Simon Critchley, the models that give us precedent for locating the interdisciplinary dialogues of poetry and philosophy are legion. With this in mind, although it may be a generalization, it is not too much a claim to begin to say that poetry and philosophy, whatever else they might be, are both enactments of a preoccupation with how the mind fashions an ordering of the world by which one can come to perceive a life-one's own life, the lives of others-lived among particularities. Poets and philosophers who go beyond boundaries of discourse in order to engage the parallel nature of these approaches seek ultimately to get at the foundations upon which these preoccupations rest.

This is not to say all poetry and all philosophy can be brought productively into dialogue with one another, of course. Nonetheless, bringing philosophy to bear on the reading of certain poets seems unavoidable for a variety of reasons-from the methodological to the thematic. In fact, in the case of discussing the work of Michael Palmer, one of the most influential avant-garde poets of the past fifty years, philosophy and philosophers are referenced commonly enough in the poems themselves (quite often through epigraphs and other tropes and devices) that the possibilities for philosophical interventions are perhaps more than a valuable approach for engaging the work; they 
are quite explicitly evoked. Palmer does, after all, open the first poem included in Notes for Echo Lake, one of the most important collections of poetry published in the 1980s, a book that interrogates the very nature of the connection between language and subjectivity, with an epigraph from Bruno Schulz's Street of Crocodiles that insists "An outlook based upon philosophy became obligatory." ${ }^{1}$ At the very least, this proclamation suggests the epistemological conditions with which the poems establish themselves. I want to consider this claim seriously in terms of what it means for Palmer's poetics, however, and I want to think of "outlook" and "obligation" as keywords because he places the epigraph so prominently at the beginning of the collection's first poem. ${ }^{2}$ Very often Palmer's work is read in terms of its formal complexity and how it reworks lyric tradition. However, this epigraph announces the poem's desire to be taken as a form of thinking that by its very nature acknowledges the literary text as a contact point between subjectivities-where one being's understanding of the limits of language encounters another's. It is a claim that the poems themselves must reckon with, even as it articulates the perspective from which the poems speak. What is an outlook based on philosophy? How does that shape perception? Also, what makes this obligatory? To what or to whom is one obliged?

If Palmer's epigraph announces the collection's investment in philosophy, it becomes important to know what tradition of philosophy it may be drawing upon in order to construct its perspective. "Outlook" and "obligation" are two words that both resonate with a particular philosophical inheritance that Stanley Cavell traced out over the course of his career insofar as "an outlook based upon philosophy" describes what we might otherwise call a philosophical mood, and such a mood is at the center of Cavell's particular interest in Ralph Waldo Emerson, whom he takes to be a philosopher of moods (Cavell 1977). An outlook is one's subjectivity traveling outwards and projecting itself onto everything, falling upon anywhere one's gaze alights. We could read the word outlook nearly literally as suggesting that one's vision moves outward. As Emerson writes in "Experience," "Thus inevitably does the universe wear our color, and every object fall successively into the subject itself. The subject exists, the subject enlarges; all things sooner or later fall into place." 3 In this way, "outlook" informs not only a writing practice that is the transposing of an experience of the world back into language, but a reading practice as well. In looking at writing, in the act of reading-if what we mean by reading is an attention coupled with active interpretation-we are then discovering our own subjectivity by means of encountering and grappling with someone else's attempts at articulating their own subjective experience. That experience of the ethics of reading is at the heart of Emerson's thinking and is the battery for any tradition that begins with him.

Cavell emphasizes such an inheritance as being American inasmuch as it is Emersonian, with the term itself not signifying any specifically nationalistic bearing. For Cavell, Ralph Waldo Emerson and Henry David Thoreau stand as the initiating figures for what it might mean to write philosophy in a mode that recognizes its debt to the past while simultaneously seeking to locate its authority in something besides a mere fealty to prior modes of thinking and their modes. What makes this American is simply - though not merely - the conditions that made such a question possible. Standing in the still early days of its existence, America needed to distinguish American thought and culture from Europe as well as from past intellectual traditions so as to be responsive to the "newness" of America and to its specific conditions. ${ }^{4}$ America was birthed from revolution, and this sense of the sovereignty of the individual and a need to question imposed authority — to push against any authority

(Palmer 1981) The line is taken from Schulz's story, "The Comet.” (Schulz 1977).

Schulz's sentence is originally written in Polish, and it would make sense for one to be reluctant to put weight on the words in their translated version, yet since Palmer uses the English version without having in mind the Polish, we are free to think about the implications of the words in English.

3 "Experience," p. 489. For the sake of convenience, all citations of Emerson are to be found in (Emerson 1983).

4 Of course, it hardly needs to be said that there were people living in North America when it was colonized and that there was a diversity of cultures present that were not Eurocentric. Still, The United States became a political entity in the 1770s, and that overwhelmed what was already present. To distinguish a country as a distinct nation is one thing, to determine its culture is another, especially as culture is one way a people shows itself to itself. Emerson's call was for thinkers, scholars, artists, and writers to produce a culture by which America could represent itself to itself, as well as to others. 
that had not earned consent—is a necessary part of how it understands itself philosophically, and how it comes to understand what philosophy might contribute to culture. As Emerson writes in "The American Scholar," "Our day of dependence, our long apprenticeship to the learning of other lands, draws to a close. The millions, that around us are rushing into life, cannot always be fed on the sere remains of foreign harvests" (Emerson 1983, p. 53). With that in mind, "American" in this context is not a descriptor of nationality so much as it identifies an originating condition calling for creative (as opposed to reactionary) thinking that actively distinguishes itself from the past by (1) not simply adhering to an ideological system that valorizes the past and tradition; and (2) investing in the belief that philosophical truths are not fixed, but remain in the process of being discovered (as Emerson writes, "the quality of the imagination is to flow, and not to freeze") (Emerson 1983, p. 463). These aspects can, then, be broadly available, regardless of one's location or nationality. ${ }^{5}$

Emerson focused on the intrinsic genius of every person as the source of legitimate insight into the qualities of Being itself. He writes in the deservedly famous opening to "Self-Reliance":

A man should learn to detect and watch that gleam of light which flashes across his mind from within, more than the lustre of the firmament of bards and sages. Yet he dismisses without notice his thought, because it is his. In every work of genius we recognize our own rejected thoughts: they come back to us with a certain alienated majesty. Great works of art have no more affecting lesson for us than this. (Emerson 1983, p. 259)

It is a bold statement to say that a work of art's greatness is measured by how it facilitates a consciousness of our own alienated thoughts. Moreover, the thoughts are both familiar, as they are our own, as well as strange, since we encounter them in another's context. Literally, the "great work of art" brings us to think again (to re-cognize) the very thoughts that we have exiled from ourselves. Art then is an aid for perceiving the movement of our own insights. The writing in essays by Emerson and by Thoreau - in its artfulness, in its idiosyncrasies - is a form of philosophy that seeks, therefore, to determine an expansive and expanding vocabulary for philosophy drawn from one's own experience rather than merely depending on redeployed, familiar habits of thought that conform to received conventions of discourse. Paradoxically, it eschews the objective-a framework which Emerson takes to be an illusion, if not a delusion-in order to find the universal.

From this perspective, Cavell might describe Emerson's writing as not just a form of philosophy but as a reform of the possibilities of philosophy, of how we might imagine philosophy could act and sound. In his being essayistic, impressionistic, and in his literary attention to style as evincing thought, Emerson undertakes a kind of writing that is attuned to its very processes of thinking and expression. In the very ways that Emerson and, by extension, Thoreau break with the conventions of philosophical writing - at least the conventions of academic, professional philosophical writing - they enact philosophical thinking. This resistance to conventions is what Emerson calls "self-reliance" and what Cavell will describe as Emerson's "aversive thinking." In its resistance to the demands of society for conformity of expression, Cavell argues, Emerson's writing expresses

his self-consciousness, his thinking as an imperative to an incessant conversion or reconfiguration of society's incessant demands for his consent-his conforming himself-to its doings; and at the same time to mean that his writing must accordingly be the object of aversion to society's consciousness, to what it might read in him. ${ }^{6}$

In "The American Scholar," Emerson insists that to gain a consciousness of self and subjectivity, and in that way lay claim to such things, to assert responsibility for our own agency, we must first forgo an unquestioning dependency on past knowledge ("the sere remains") as that breeds repetition rather than creation, fosters reiteration rather than imagination. Instead, writes Emerson,

5 The fullest account of Cavell's thinking of this can be found in his essay "Finding as Founding" in (Stanley Cavell 1981).

6 "Aversive Thinking: Emersonian Representations in Heidegger and Nietzsche," (Cavell 1990). 
Whatever talents may be, if the man create not, the pure efflux of the Deity is not his; cinders and smoke there may be, but not yet flame. There are creative manners, there are creative actions, and creative words; manners, actions, words, that is, indicative of no custom or authority, but springing spontaneous from the mind's own sense of good and fair. (Emerson 1983, p. 58)

Cavell reads such insistences "to create" as a call to stop turning away from one's own inspiration, away from one's own intuition, in order to discover or recover one's relationship to the ordinary and the everyday, "something which for Emerson," writes Cavell, "is the same matter of salvation in the intellectual life as it is in the religious life" (Cavell 1977, p. 148). Experience, Emerson argues, then becomes the arbiter for what it means to know. "So much only of life as I know by experience," Emerson writes, and then adds that experience "is the raw material out of which the intellect molds her splendid products. A strange process too, this by which experience is converted into thought, as a mulberry-leaf is converted into satin" (Emerson 1983, p. 60). That is, the stuff of one's life is the grounds, the conditions for philosophy to take root. Ultimately, I would argue, this describes an "outlook of philosophy" that is "obligatory" to the extent that it we have an obligation to ourselves to know ourselves.

With this context in place, I want to look at the possibility that Palmer's poems link with, and overlap with, American philosophy—at least the kind found within a Cavellian key—regarding its interest in what we might otherwise call "mood" or "outlook." In saying this, however, I am not citing influence - direct or otherwise — of a certain strain of philosophy on the poems, but will bring out the way that we might read and locate Palmer's work within an American literary/philosophical continuum and indicate how reading the work within that context matters in regards to how that opens up the work to a range of important existential and experiential implications by suggesting that subjectivity-even one's own-is a text ever being written and ever being read. Such a move has a great deal to do with what it means to say that an outlook based on philosophy has become obligatory and what that has to do with poetry.

My placing Cavell and Palmer in conversation is not happenstance. ${ }^{7}$ Beyond their shared elective affinities, Palmer was at one time Cavell's student. Within the context of this forum on literature and ethics, it is most likely not necessary to introduce Stanley Cavell, a contemporary philosopher whose importance and influence has continued to deepen over the last two decades; it is, however, useful to give some context for Palmer. Born in New York City in 1943, Palmer was educated at Harvard and Columbia. The author of numerous books of poetry including Codes Appearing: Poems 1979-1988 (2001); The Promises of Glass (2000); The Lion Bridge: Selected Poems 1972-1995 (1998); At Passages (1996); and Sun (1988), Palmer is undoubtedly one of the most important experimental poets of his generation with Notes for Echo Lake, published in 1981, being one of his most influential collections. Although critics often place Palmer alongside the Language poets of the 1970s and 80s, a group of experimental writers including Charles Bernstein, Bruce Andrews, Lyn Hejinian, and Ron Silliman (just to name a few), who often drew on elements of Russian formalism and Marxism to create a form of counter-lyric poetry.

Although linked to these writers due to social connections, particularly in San Francisco, one of the hubs of radical poetics in the U. S., Palmer is perhaps more accurately described as an inheritor of the poetics of the New American poets of the 1950s and 1960s, such as Robert Duncan, Robert Creeley, and George Oppen. Throughout his career, Palmer has been less invested in the polemics

7 It is important to note that Palmer is not the only poet whose work has been shaped by an encounter with Cavell's philosophy. Poets from John Hollander to Susan Howe and Ann Lauterbach have acknowledged their interest in how Cavell's philosophical interventions have been generative in terms of thinking about language and the ways that it describes the possibilities for an ethics of reading. Charles Bernstein has frequently acknowledged Cavell as his mentor, their close relationship having begun with Bernstein's own undergraduate days at Harvard in the 1970s. It is well beyond the scope of this essay, but there does seem to be a need for a sustained investigation into the ways that Cavell's thinking-directly and indirectly-has impacted American poetry over the last few decades. 
of Marxist literary theory than other Language writers have been, and he rarely treats poetry as the means of opening up the possibilities of ideological critique in the ways that such contemporaries as Bruce Andrews or Ron Silliman might. Palmer himself will cite Duncan and Creeley as direct mentors and acknowledges his presence at the 1963 Poetry Vancouver Conference, a landmark gathering of such figures as Charles Olson, Creeley, Allen Ginsberg, Denise Levertov and others of what would be called New American Poetry as a pivotal moment for him in terms of his exposure to the possibilities of a radical poetics that remained committed to aesthetic experience. ${ }^{8}$ In an interview in 2006, Palmer described the arc of his work as,

moving a little bit away from radical syntax into the mysteries of ordinary language, in the philosophical if not every day sense. It probably looks less unusual on the page. And I've been interested in the infinite, ingathering potential of the lyrical phrase-not confession, but the voicing of selves that make up the poetic self, from Greek lyrics to the Italians, to modern poets like Mandelstam. (Bullock 2006)

Arguably, however, Palmer's sense of the lyric as being primarily the representation of subjectivity finding itself through language is consistent throughout his career and is what differentiates him from many of the Language writers who sought instead to decolonize language and "denaturalize" conceptions of poetic voice and authenticity by laying bear the mechanisms of ideology that are encoded within traditions of the lyric. Although he shares with other Language poets an interest in disjunction, fragmentation, and formal complexity, the underlying impulses are quite distinct. ${ }^{9}$

This interest in the "mysteries of ordinary language" is one of the ideas that ties Palmer to Cavell, a foremost figure in Ordinary language philosophy. In 1965, Cavell served as one of the readers for Palmer's senior project at Harvard College, a long paper analyzing the work of the proto-surrealist French author Raymond Roussel. In many ways, Palmer's early association with Cavell was pragmatic and somewhat ad hoc: Harvard at that time had the policy that faculty could choose, from a pool, which undergraduate projects they could and would be willing to advise. In effect, Cavell was late to choose and took on Palmer's project by default. That initial relationship between Cavell and Palmer was more a practical arrangement than the product of ongoing tutelage or mentoring. Indeed, although Palmer had occasionally joined the philosophy tables Cavell ran in those days, he never actually contributed, preferring to be what these days we would call a "lurker." That is to say, until the senior project, the two had never actually had a substantive conversation. After working together on the senior project, a friendship did take root and Palmer would be a regular reader of Cavell's work as it began appearing in the 1970s and onward. Although the connection between this particular philosophical poet and this poetic philosopher is almost definitively anecdotal, it does provide an interesting entry point, if not justification, for thinking about the ways that Palmer's poetry, specifically Notes for Echo Lake, might be read through the lens of Cavell's work on the intersection of language and ethics that starts appearing in 1970 and becomes so crucial in the 1980s.

The connection between Palmer's Notes for Echo Lake and Cavell's philosophical work of the time is especially compelling if we also consider that Notes for Echo Lake came out the same year (1981) and with the same press (North Point) that published the expanded version of the seminal Senses of Walden, Cavell's philosophical reading of Henry David Thoreau. Cavell first wrote Senses of Walden in 1970, just a few years after he had worked with Palmer at Harvard. The reprinted version appeared with the addition of two important essays about Ralph Waldo Emerson and the book is Cavell's first sustained attempt at discovering through these two 19th century writers the ways that America began to express

8 "New American Poetry" is a loose descriptor that is shaped by the Donald Allen anthology of that name published in 1963, a collection that sought to establish a context for various strains of post-war avant-garde poetry in the U.S.

9 Of course, Language poetry was not a monolithic school or movement so much as it was a network of elective affinities, and so any number of exceptions and counterexamples can be offered in describing what might constitute the basic constellation of poetics that held these figures together in conversation. It is Palmer's interest in expanding notions of lyric subjectivity rather than the dismantling of it that sets him apart. 
itself philosophically in a mode that was distinct from a European body of thought that stretched back centuries. ${ }^{10}$

There is also another perhaps less obvious triangulation between Thoreau's Walden and Notes for Echo Lake in terms of narrative sequencing in the way that Palmer collapses a longer period of time into a single year, just as Thoreau had done in his own book. In a talk from 1982, Palmer states, "At some point in working on Notes for Echo Lake I realized that the 'notes' themselves should number twelve and that the larger period, so-to-speak, of the book would be a year, an entirely metaphoric year since the book is drawn from work extending over about three years."11 This time of relative seclusion as the condition for writing a book is not limited to Palmer and Thoreau. Cavell wrote both Senses of Walden and The World Viewed, his landmark study of film as a form of philosophy, during a year he spent as a fellow at Wesleyan University's Humanities Center, withdrawing from Cambridge, MA, to the somewhat quieter village of Middletown, CT. In essence, Cavell had no commitments that year and worked all day at a kitchen table, free from the usual distractions of teaching and departmental toiling. Let us call these moments of overlapping biographical resemblances resonances, or perhaps echoes, occurring between Thoreau, Emerson, Cavell, and Palmer.

Yet, these texts signal a shared sense of how a specific place becomes generative in terms of its serving as a meditative space, which in part establishes the conditions for a philosophical outlook that takes on an ethical dimension. "A writer in meditation is literally a human being awaiting expression," Cavell notes in his reflection on Thoreau's withdrawal to Walden, the pond itself, and that author's withdrawal into Walden, the text he is writing (Cavell 1977, p. 59). In "Notes for Echo Lake 3," Palmer, commenting on a kind of silence from a "he" who remains undefined, writes, "In silence he would mark time listening for whispered words" (Palmer 1981, p. 17). The "he" perhaps remains unnamed and undefined-a pronoun in search of a noun—because he is listening. The formation of an identity comes after that, when the listening is turned outward and becomes expression. As Emerson writes in "The Poet," "The man is only half himself, the other half is his expression" (Emerson 1983, p. 448). Palmer complicates this conception of subjectivity even further, "And I as it is, I as the one but less than one in it" (Palmer 1981, p. 15). The words of one's experience, whispered from the interior, are what await expression, and the articulation of that experience, by such means made available to others, is a way that one manifests one's subjectivity.

The idea that we must express to come to some sort of wholeness is compelling, and we might come to wonder about how that expression might be received. As Thoreau writes in Walden, "I, on my side, require of every writer, first or last, a simple and sincere account of his own life, and not merely what he has heard of other men's lives; some such account as he would send to his kindred from a distant land; for if he has lived sincerely, it must have been in a distant land to me" (Thoreau 1992). The acknowledgement of one's own subjectivity becomes the means by which others-by comparison and through contrast - can come to recognize their own. With that, however, comes the risk of not being heard. A "Sign that empties itself at each instance of meaning, and how else to reinvent attention," writes Palmer in "Notes for Echo Lake 1" (Palmer 1981, p. 5). Is it the emptying out of one's self-the expression-that creates the possibilities for one's own attention to others? Or is it that the emptied sign calls for another's attention?

The untethered referent "he" of Palmer's line, "In silence he would mark time listening for whispered words" is not the only challenge in reading the work. The poems of Notes for Echo Lake are often largely comprised of paratactic statements, fragmented sentences, and free-floating aphorisms. Take this passage from "Notes for Echo Lake 3" as representative:

10 In the preface to Senses of Walden, Cavell will explain that in turning to Thoreau he hoped to find a moment before the radical split between the English and German traditions of philosophy "began to shun one another" so as to find the means to "reenact an old exchange between these traditions," p. xiv.

11 "Period [senses of duration]," in (Palmer 1983). 
The letters of the words of our legs and arms. What he had seen or thought he'd seen, within the eye, voices overheard rising and falling. And if each conversation has no end, then composition is a placing beside or with and is endless, broken threads of cloud driven from the west of the afternoon wind. ${ }^{12}$

In some ways, this passage is recognizable in regards to its vocabulary-the words themselves are common enough-yet in grammatical terms, the words don't easily knit together to indicate the expected sequencing of either an argument or a developing narrative. Nevertheless, it feels meaningful, perhaps because of that fact of its being between straightforward legibility and obscurity. Such a situation demands interpretation, and we begin by interrogating the language itself-that is, how the words mean. This is true not only of texts, but of life, yet a it is a poem whose very existence, pace Modernism, is predicated on the belief that activating the polysemous nature of language is a necessary condition for representing the world's complexity of meaning. Called to such effort, "[when] the mind is braced by labor and invention," writes Emerson, "the page of whatever book we read becomes luminous with manifold allusion. Every sentence is doubly significant, and the sense of our author is as broad as the world" (Emerson 1983, p. 59). In "Notes for Echo Lake 11," Palmer writes in a variation on Emerson's theme, "Words listen to the words until you hear them," which itself is a way of describing the self-conscious process of interpreting, as we use our understanding of words as the means of trying and sounding the depths of the words whose meanings are unknown though the words themselves be familiar.

Without the guidance of a clarifying or determining apparatus of a larger narrative to offer context, within the sentences we start to see the poem commenting on itself. Turning to the passage from Palmer that I cited earlier, we might begin, say, in reading "the letters of the words of our legs and arms" by noting that legs and arms are part of our body language and their position communicates desire or fear or openness or distrust—or all these at once. "Eye" is a homophone with "I," which is where our acts of perception take place. Conversations are not necessarily composed; they occur and develop and so do not have a proper ending. In the end of Palmer's prose poem, we find a single sentence: "In the poem he learns to turn and turn, and prose always seems a sentence long" (Palmer 1981, p. 17). The line plays with the notion of verse and also "conversation," indicating their shared etymology in the Latin word for "to turn." That is, "if no conversation has an end," it too will continue to turn and turn. The line itself being itself a sentence, points back to itself, precisely because of the fact that although it looks like prose, it does not behave like prose. The self-reflexivity does not necessarily lead to an endless loop, but rather gets us to think about the very nuances of the word and how we determine the meaningfulness of their conversation. This process never ends if we never come to certainty but keeps turning and turning. Cavell might see this as a manifestation of an Emersonian moral perfectionism. ${ }^{13}$ That is, since we never reach an end, there is an openness that remains open.

Such openness remains important if legibility and interpretation is counted as part of how we determine the nature of the world and our relationship to it. In Palmer's "The Comet," the opening poem of Notes for Echo Lake, the world is represented as a textual space to be read: "That year the end of winter stood under a sign. All days were red in the margin/ writ large against the ochre rooftops ...." (Palmer 1981, p. 1). In the homophonic slippage of "red" the color and "read" as the past tense of "to read," Palmer also calls to mind the ways that, conventionally, textual corrections are made in the margins with red ink while at the same time that pun foregrounds the word as a signifier-the lexical "a," a visible but unheard difference, that might set us up for a misreading, substituting "red" for "read." Which sounding of the word is the mistake and which is the correction? In a later poem in the collection, Palmer offers a sentence that is in the form of a question but does not actually end with

12 (Palmer 1981, p. 12) Cavell offers an interesting discussion of "being next to" or neighboring or "nextness" in regards to one's sense of nature, landscape (neighbors), and ourselves when we grow self-conscious in (Cavell 1977, pp. 104-10).

13 The fullest discussion of Cavell's understanding of Emersonian moral perfectionism is to be found in Conditions Handsome and Unhandsome, beginning with the extensive introduction. 
a question mark: "Or was the question in the letters themselves, in how by chance the words were spelled." Palmer seems to be underlining the arbitrary nature of the structure of words and what the telling difference comes to when small differences are brought to the fore. It has a skeptical force: "how do I know which red (or read) you mean"? Arguably, it is because of the ever-present uncertainty of communication and incomplete expression built out of language that never escapes inexactitude that the impetus for conversation continues and never really ends.

Earlier I was suggesting that the meditative space of Echo Lake or Walden, or perhaps Middletown, $\mathrm{CT}$, are places that are important for the ways that they create meditation from which flows expression. I say that place is important, and yet Notes for Echo Lake begins with an epigraph from Augustine that troubles that claim: "Place there is none; we go forward and backward, and there is no place" (Palmer 1981, n. p.). Might that be an argument against the specificity of place? It is hard to read it in any other way. Yet in the context of Augustine's confessions, these lines indicate that there is no outside, no division of one place from another place, except subjectively. Or as we see in the first poem, a prose poem, of Palmer's "Echo Lake" series, "If one lives in it. 'Local' and 'specific' and so on finally seeming much less interesting than the particular wherever that may locate" (Palmer 1981, p. 4). We note that "particular" in being particular also always reminds us of its being part of something larger. By extension, this applies to one's subjectivity in regards to its situation. "I am dependent on everything," says the speaker of Palmer's "Notes for Echo Lake 11" and if we are reading the poems as being also a meditation on writing, then this is not simply an expression of the self but is also a description of grammatical construction (Palmer 1981, p. 69). In other words, the personal pronoun, that which is named by " $\mathrm{I}$ " is such, as such, only in relationship to the things and people around it. As Cavell writes, "language is everywhere we find ourselves," which I take to mean that we find ourselves, the selves that we are, in language through language. This brings again to mind, "Words listen to the words until you hear them."

Allow me to linger a bit more over Palmer's quoting Augustine since it raises the question of what debt the epigraph creates between where it is cited (Palmer's book of poems) and the source text. How much, for instance, of a transcendental sentiment or tendency is imported with those lines and then grafted onto the poems that follow? Or perhaps we might ask this another way: Is Palmer's book of poems then a form of spiritual meditation, a genre both signaled and activated by its opening citation, which is drawn from just such a text? If Notes for Echo Lake is indeed such a meditation, and the citation seeks to place it within that tradition, then what follows that epigraph-that is to say, the poems themselves - offers a different version of what one means when one says "spirit" as well as meditation, a form of inquiry that is not religious, yet no less deeply felt. The same can be said of Walden.

Inasmuch as Augustine's confessions move between philosophy, theology, and biography_-between rhetoric and narrative-so too do Palmer's poems, through this engagement with relationships based on, built out of language- - which is to say all relationships. I raise the possibility of the poems being a form of meditation because the problem of the epigraph and the relationship between texts remain connected to the idea of how a poet inherits a tradition, crafts a genealogy-how he or she wishes to be heard and to whom he or she is addressing such acts of language. These issues have other implications as well, because the unsettled space between poetry and argument-based claims might be a space for a certain kind of philosophy, or at least what we might call "thinking," and even the emphasis that the poems are "notes" suggests that the work acknowledges at every moment that it is writing, that the notes are the mechanisms of language that point to their incompleteness. Being caught between those modes of the philosophical and the literary might call for an "outlook based on philosophy." When I say that these are modes, I do not merely mean they are forms of writing, but rather are the kinds of thinking that attend, that are enacted through the writing itself. In this way, Palmer's work is not a form of philosophy, but it is an activity of language that by way of its difficulties acknowledges that philosophy and ethics underwrite all interpretive processes. The poems share with Emerson a certain resistance to conformity that requires the reader fall back on his/her/their 
own experiences with words and how they mean in order to find some shared sense of language, some glimpse into what we do and do not share as common experience.

So what are we to make of (make out of) the thinking of Notes for Echo Lake? From the beginning, we see a title that indicates that there is a form of address (the notes are intended for, addressed to Echo Lake). Or is it best to read the work as something else if we take the other meaning of "notes"? I also take this as the first step in seeing the poems as being about the act of writing, the attempt to bring experience back into language, and therefore to make language itself an experience of itself. Behind the title, we might hear Wittgenstein's description of Philosophical Investigations as "sketches of landscapes" (Landschaftskizzen). ${ }^{14}$ That is, we would take it that the poems are notes, drafts, sketches that point towards representation, and specifically the representation of something coming to be, an expression of futurity - as if to say the poems are notes that will represent what is to come, in this case, a "new yet unapproachable" Echo Lake. ${ }^{15}$

Both readings of the title are possible. In the first place, the poems then are the address that pushes back to the origin of the words, lines, and sentences. The address, in other words, reveals the addresser's sense of language and ethics - the sense of how to approach the addressee in language is enacted by, expressed by the language and the particulars of its use. Address creates a relationship and the language reveals the architecture, the poetics-the ebb and flow of ethical responses, the shuttling of perceived debts and obligations between the addresser and the addressee. "Who did he talk to/Did she trust what she saw/Who does the talking/Whose words formed awkward curves," Palmer's propositional, interrogative lines both ask and posit in "Notes for Echo Lake 4" (Palmer 1981, p. 22). In this case, the complex syntax at work in Palmer's poems reveals that the addressee is not easily described as a "voice" or a "speaker," if we are to imagine those tropes conjured by these terms as stable, consistent, and continuous figures. But why is it we would be apt to assume that a "voice" —any voice-is that consistent, that stable? We might say that the speaker is not the origin of a word-that is, a word's meaning does not derive specifically or at least not wholly from the person saying it. Rather, the voice provides a location, a context for the words. It arranges without defining, or that definition is never settled as it comes to test the terms of its arrangement at each moment.

In his essay "Autobiography, Memory and Mechanisms of Concealment," Palmer includes a long discussion of Augustine, and offers the reading that insists, "Augustine investigates both the subject-object relationship in discourse and the structural relationships that constitute the linguistic sign in order to reveal what he is doing, to confess the nature of his activity" (Palmer 2008). In other words, with other words, according to Palmer, Augustine's self-interrogation confesses that all language is mediated. Yes, one wants to say, but what is part of that mediation? What necessitates negotiation and interrogation, self or otherwise? This is the question of whether or not we can communicate that revelation to the Other. "The relationship between signifier and signified must be reconstituted at each moment of the act of telling, in a constant state of uncertainty," writes Palmer. ${ }^{16}$ That state of uncertainty is what we might call skepticism. If we need to constantly restate and rediscover how our words mean, then we always have to find the means and conditions for what we say so that others might hear or acknowledge what we have to say.

I have not forgotten that my rationale for wanting to place Palmer's work in dialogue with Cavell arises not simply because of some personal history they shared or because I necessarily want to foreground some regional element of these poems by Palmer, a poet who is usually read in a consciously - even self-consciously_cosmopolitan and international context. My emphasis on that

14 Wittgenstein calls his remarks "eine Menge von Landschaftskizzen" ["a set of landscape-sketches"] in the preface of his book. (Wittgenstein 2001).

15 I am alluding to both Cavell's book This New Yet Unapproachable America as well as a passage from Emerson's essay "Experience": "I feel a new heart beating with the love of the new beauty. I am ready to die out of nature, and be born again into this new yet unapproachable America I have found in the West." (Emerson 1983, p. 485).

16 Ibid., p. 276 
element of "America" that is "American thought" is shot through with a double need of determining the ground by which one makes claims (for others or for ourselves) and of doubting the grounds for those claims at the same time. Cavell describes the situation this way:

Any American writer, any American, is apt to respond to [America's declaring its independence] in one way or another; to the knowledge that America exists only in its discovery and its discovery was always an accident; and to the obsession with freedom, and with building new structures and forming new human beings with new minds to inhabit them; and to the presentiment that this unparalleled opportunity has been lost forever. (Cavell 1977, pp. 8-9)

He will go on to say that Thoreau's writing — and by the extension all American writers of the tradition I have been sketching out- "must admit this pressure and at every moment resolutely withstand it," adding further that it "must live, if it can, pressed between history and heaven." With "admit" we see Cavell saying that the pressure must be allowed into the work, but also that pressure must be confessed. Thus, the state of uncertainty that Palmer describes in Augustine, that he clearly enacts in the ambivalences of the syntax of Notes for Echo Lake (with "Words that come in smoke and go," Palmer says in "Notes for Echo Lake 3"), may also amount to the pathos that Cavell describes as something inherent in American philosophy that comes to us from Emerson and Thoreau and then gets absorbed and redistributed back through Nietzsche and Heidegger, among others (Palmer 1981, p. 17). Although Palmer himself may again and again invoke European thinkers and philosophers-just as Thoreau or Emerson do as well-he does so to create his notes for Echo Lake, the poems that will add up to an experience of (but not be reducible to) a specific place in America, as if to indicate that Echo Lake still is left unfounded even if we know where to find it. This need to discover where one is-“Where do we find ourselves?" Emerson asks at the beginning of his essay "Experience"—suggests that we can never simply be where we are, since to name it is to begin to place ourselves outside of the experience. This also seems to be evoked in the reference to Augustine.

Now that I have highlighted the problems of language and identity that Palmer wrestles with in his poems, let me place the conversation in another frame that has to do with skepticism. I turn to Cavell's essay "Finding as Founding," one of his most crucial readings of Emerson, for a passage that seems to echo the claims of Palmer's I cited just a moment ago. Cavell writes,

The feeling as if we have to penetrate phenomena is evidently produced by a feeling of some barrier to or resistance in phenomena (as if the conditions of a thing's appearance were limitations in approaching it; as if skepticism accurately registered the world's withdrawal from us, say it's shrinking) as if language has difficulty in reaching phenomena, let alone grasping them. (Stanley Cavell 1981, p. 88)

Cavell is responding to a moment in Wittgenstein's Philosophical Investigations: "we feel as if we had to penetrate phenomena."17 This acknowledgment of language's difficulty is threaded through Notes for Echo Lake and is in part enacted by the ways that the poem's language is at times so difficult to understand. In a passage that seems colored by Cavell's comments, Palmer writes in the poem "Seven Lines of Equal Length":

The simple past has weight

but where are the fountains you spoke of

17 (Wittgenstein 2001, p. e36.) Cavell is using Anscombe's translation, which translates "Erscheinungen" as "phenomena". It also can be translated as "appearances," which seems relevant given the references to eyes and eyesight throughout Notes for Echo Lake. Furthermore, in this section, Wittgenstein himself cites Augustine: "Thus Augustine calls to mind the different statements that are made about the duration, past, present, or future, of events. (These are of course not philosophical statements about time, the past, the present, and the future.)". 
she wonders in perfect innocence

and the flowering trees

and what is the word that stands for these things

he asks her between the branches. (Palmer 1981, p. 43.)

That compulsion to use language to get beyond language is what we might call a will to know, though in reality, through our efforts, we draw near not the phenomena themselves but the kinds of statements we make about phenomena. The compulsion to name a thing exactly-and we feel it often enough in moments of great pleasure, joy, grief, and horror-might be a Romantic one, granted, but it would be a problem insofar as it is inadequate and unsatisfying, to halt just there, to stop in stupefaction, gobsmacked, as it were. There is a further step one can take in the face of the compulsion, the endlessly frustrated will to know, the awe that this is a version of skepticism. For instance, this is how Emerson describes this sense of a prevailing somewhat unanswerable skepticism around language: "I know that the world I converse with in the city and in the farms, is not the world I think. I observe that difference, and shall observe it. One day, I shall know the value and law of this discrepance" (Emerson 1983, pp. 491-92). We see here a sense of that next step. Emerson does not drive towards resolving the discrepancy between word and thing, language and experience, but towards knowing the value of that gap and what the endless deferral offers us, which is at last a reason to keep trying.

In the self-reflexivity and self-consciousness of Palmer's poems, we see reflected the conditions by which poetry both offers a possibility - what we might call hope-of connection and address to the Other even while it exposes to doubt that same possibility that we can ever reach the Other. With that doubt in mind, we can see Palmer's participation in that "reformation of philosophy" that Cavell describes. It does not stand outside of that struggle but manifests it. One limitation of philosophical discourse is that in its insistence on its own logicality, it seeks to be objectivity. Palmer's poetry does not describe the obligation of a philosophical outlook, but establishes the conditions by which we note ourselves seeking out a way of understanding our own frustrations with language, what causes these frustrations, and how we might navigate them. I almost hesitate, though I suppose that is itself a hesitation, to say that what we hold in common is that doubt. This might be, then, what philosophy can learn from poetry. That which holds us apart is what binds us fast. It seems that this connection built on shared distance has something to do with the obligation of having an outlook based on philosophy. As I posited it earlier, to what and to whom are we obligated? Ourselves? Others?

In essence, then, if we often ask how philosophy flows into poetry, we might just as well ask how poetry and literature flow into philosophy? Poetry, particularly Palmer's, does not offer an argument or a consistent worldview, but it does enact the difficulties of interpretation that happen at the most local and specific level. Rather than ignoring or overlooking skepticism and the failures of expression, poetry foregrounds these conditions as the very medium of daily life and poetry's difficulties are amplified versions of the problems that are shot through the language we use to represent everyday life to others as well as to ourselves. We return, then, to the obligation of a "philosophical outlook," which Palmer's book positions as a call for acknowledging how we attune ourselves to the demands of language.

Within the frame of such an essay, I should perhaps offer, given the compactness of the context, something specific, a clear, portable, reading; however, I am arriving at perhaps even more questions, certainly more ambitious questions than I began with. To a certain degree, that seems most apt, given that Palmer's poems are themselves "notes." Call this a reader's notes, then: noting what I read, reading how I note.

At the outset of Senses of Walden, Cavell asks, "what hope is there in a book about a book"? (Cavell 1977, p. xiii.). His question is related to seeing how one philosophical text is prompted by another, and that, largely, is something I see having happened in Notes for Echo Lake-it is a book of prompted articulations and prompting provocations in its deployments of fragments and aphorisms; it is a book of poems about writing and reading in the largest sense, that is, the negotiating of the 
ways that we negotiate meaning. What Cavell's philosophy tells us about language is parallel to what Palmer's poetry tells us about language: words are an unsettledness that seeks to ground itself in experience. In the processes of discovering our acts of interpretation, the warp and hew of how we read, in fits and spurts, it is not simply the words, but how we hang them together with a kind of hope of drawing the attention of the Other through what is recognizable as well as what is opaque that creates a conversation about how we recognize the Other or how, imperfectly, we recognize ourselves through the Other-through that which returns via an echo of our soundings, or what Emerson states as the fact that "In every work of genius we recognize our own rejected thoughts: they come back to us with a certain alienated majesty. Great works of art have no more affecting lesson for us than this." We recognize ourselves by way of that unfamiliarity, that intimate strangeness. Notes for Echo Lake locates itself, its language, the same way we might be called to read it in a series of echoes and locations. What we read is the proximity and distance of texts and words. The poems provide a place for our encounters with our limitations of language as readers, as language workers, a space built from our continued hope against that impossibility of knowing and saying exactly, in persisting against that again-and-again face of failure that measures the shape and sound of what it means to be human at this time and in this place.

Funding: This research received no external funding.

Conflicts of Interest: The author declares no conflict of interest.

\section{References}

Bullock, Ken. 2006. Arts: Michael Palmer and Douglas Blazek Read at Moe's. The Berkeley Daily Planet, April 7. Available online: http://www.berkeleydailyplanet.com/issue/2006-04-07/article/23854 (accessed on 18 May 2019).

Cavell, Stanley. 1977. The Senses of Walden: An Expanded Edition. San Francisco: North Point Press, p. 151.

Stanley Cavell. 1981. This New Yet Unapproachable America. Albuquerque: Living Batch Press.

Cavell, Stanley. 1990. Conditions Handsome and Unhandsome. Chicago: Univerist of Chicago Press, p. 37.

Emerson, Ralph Waldo. 1983. Essays and Lectures. Edited by Joel Porte. New York: Library of America.

Palmer, Michael. 1981. Notes for Echo Lake. San Francisco: North Point Press, p. 1.

Palmer, Michael, ed. 1983. Code of Signals: Recent Writings on Poetics. Berkley: North Atlantic Books, p. 262.

Palmer, Michael. 2008. Active Boundaries: Selected Essays and Talks. New York: New Directions, p. 276.

Schulz, Bruno. 1977. The Street of Crocodiles. Translated by Celina Wieniewska. New York: Penguin, p. 143.

Thoreau, Henry David. 1992. Walden and Other Writings. Edited by Brooks Atkinson. New York: Modern Library, p. 3.

Wittgenstein, Ludwig. 2001. Philosophical Investigations, 3rd ed. Translated by G. E. M. Anscombe. With the German Text. London: Blackwell.

(C) 2019 by the author. Licensee MDPI, Basel, Switzerland. This article is an open access article distributed under the terms and conditions of the Creative Commons Attribution (CC BY) license (http://creativecommons.org/licenses/by/4.0/). 